\title{
Traditional methods of food habits and dietary preparations in Ayurveda-the Indian system of medicine
}

\author{
Dhanya S., Ramesh N V and Abhayakumar Mishra
}

\begin{abstract}
Ayurveda (the science of life) is one of the branches of Vedas. It is regarded as upaveda of Atharva Veda. It is a steam of knowledge coming down from generation to generation since eternity parallel to Vedic literature which is why its emergence has been said to be from the creator (Brahman) himself prior to the creation. It is taken as eternal because nobody knows when it was not there. In Ayurveda, food is considered to affect the mind as well as the body. By understanding how to prepare foods best suited to our minds and bodies, we can utilize nutrition as a source of healing. Food is the most essential to sustain a good life and the same food if consumed inappropriately becomes the root cause of many diseases. So, proper knowledge about food and its importance should be known by all human beings to have better benefits from it.
\end{abstract}

Keywords: Nutrition, Anna, Yusha, Takra, Ahara, Sattvic diet

\section{Introduction}

Ayurveda believes that ahara articles are composed of five mahabhutas and respective bhutagnis digest their own ingredients during the process of digestion and metabolism but only when they are stimulated by antaragni. Traditional wisdom about the processing of food, its preservation techniques, and their therapeutic effects has been established for many generations in India [1]. Classical Ayurveda texts cover an array of themes on food ranging from the diversity of natural sources, their properties in relation to seasons and places and to their specific function both in physiological and pathological states [2]. Foods and drinks with desirable smell, taste and touch and having been taken according to the prescribed method are said as vital strength by the experts on the basis of observing their results directly because the condition of internal fire depends on their fuel. They produce energy in mind, the constitution of dhatus, strength, complexion and clarity of sense organs, if properly taken; otherwise, they become harmful [3].

\footnotetext{
* Correspondence: dr.dhanyaranjit@gmail.com

Department of Rasashastra and Bhaishajyakalpana (Medicinal Chemistry and Pharmacy), Amrita School of Ayurveda, Amritapuri, Amrita Vishwa

Vidyapeetham, Coimbatore, India
}

\subsection{Basic principles of Ayurvedic nutrition}

Nutrition is the most important because from a proper wholesome and balanced diet, all the body constituentsdosha, dhatu and mala-are formed. That is why it is said that 'we are what we eat'. Food is not only essential for our physical well-being but it provides nutrition for our mind as well.

In Upanishad, it has been stated that the food we consume gets divided into three parts. The gross part is converted into flesh and a subtle part nourishes the mind. It is also stated there that the water we drink also gets divided into three parts. The major part becomes urine, the middle part becomes blood and the subtle part nourishes our life force or prana.

\subsection{Emphasis laid by Vedic (ancient Indian) literature on ahara kalpana}

Vedas were not the aushadha granthas, but like encyclopedias, they included everything relevant. Man always is behind the taste in the food he consumes. As we try to make delicious food items out of different vegetables available, in the same way in the Vedic period, also man might have tried out different ahara kalpana. 




Fig. 1 Sattvic diet

Different anna kalpana are prominently referred in Vedic literature. Yava (a type of grains) has reference in many contexts-Rigveda, Yajurveda and Atharva Veda.

Dhana (fried yava dhanya), karambha (churned food items), saktu (roasted flour), parivapa (roasted grains), payas (milk), dadhi (curd), soma (dravya visesha), amiksha (milk + curd), vajina (liquid part while preparing amiksha) and madhu (honey) are few of the names of ahara dravya in use during the Vedic period. In different contexts, direct references for madya kalpana (fermented preparations), payasa, dadhi, navanita, sarpi, parivapa, laja, saktu, karambha, odana, etc. are found in Vedic literature.

\subsection{Emphasis laid by Samhitas (ancient Ayurvedic texts) on ahara kalpana}

Ayurvedic Samhitas (ancient Ayurvedic texts) are described in detail about the concept of ahara kalpana with details of its properties and uses as per context. It also includes the advanced methods and articles for preparation of ahara kalpana.

\subsubsection{Food habits in Sushruta Samhita}

According to Susrutacarya, one should eat the proper quantity of food at the proper time by sitting on a raised platform. After meals, we should sit comfortably like a king and then have a short walk. On eating, first, we should take a sweet taste, then salt and sour tastes and then pungent, bitter and astringent tastes. Sweet taste helps to overcome vayu in the stomach in a hungry person; salt and sour tastes stimulate the digestive fire; and the pungent, bitter and astringent tastes taken in the end subdues kapha dosha. Also, some fruits taken in the beginning help to overcome vata dosha. Indian gooseberry is recommended to take in the starting, middle and end of the meal. One should take heavy foods up to one-third of the fullness and light foods can be taken up to satiation.

\subsubsection{Food habits in Charaka Samhita}

Charaka Samhita Sutrasthana 27th chapter (Annapana Vidhi Adhyaya) explains about various types of grains and pulses; various types, qualities and benefits of fruits and vegetables, milk and dairy products, sugarcane preparations, honey; and its types, waters, wines. etc.

Food articles are classified according to the following 12 groups: Shuka dhanya (grains), Shami dhanya (pulses), Mamsa varga (meats), Kshira varga (milk and milk products), Shaka varga (vegetables), Phala varga (fruits), Harita varga (green leafy vegetables), Jala varga (waters), Taila varga (oils), Ikshu varga (sugarcane products), Krutanna varga (prepared foods).

In this chapter, Acarya is also explaining about properties of foods and drinks in general, ingredients having foremost qualities, postprandial drinks along with their properties, brief statements on heaviness and lightness of foods ingredients, etc.

\subsubsection{Food habits in Ashtanga Hridaya}

Vagbhatacharya insists to take the food sitting on the floor. According to him, this intensifies the digestive fire. And also, the food plate should be kept a little bit above the floor. At noon time, one can take lighter meal, juice or buttermilk. We should take our evening meals while the sun is still out. According to Acarya, we should have our dinner before sunset, as the digestive fire becomes dormant once the sun sets. We should practise lying down on our left side after eating. Lying on the left side activates the pingala (soorya) naadi on the right side of the body. Activation of pingala nadi in turn activates the digestive fire. He recommends us to take only liquid 


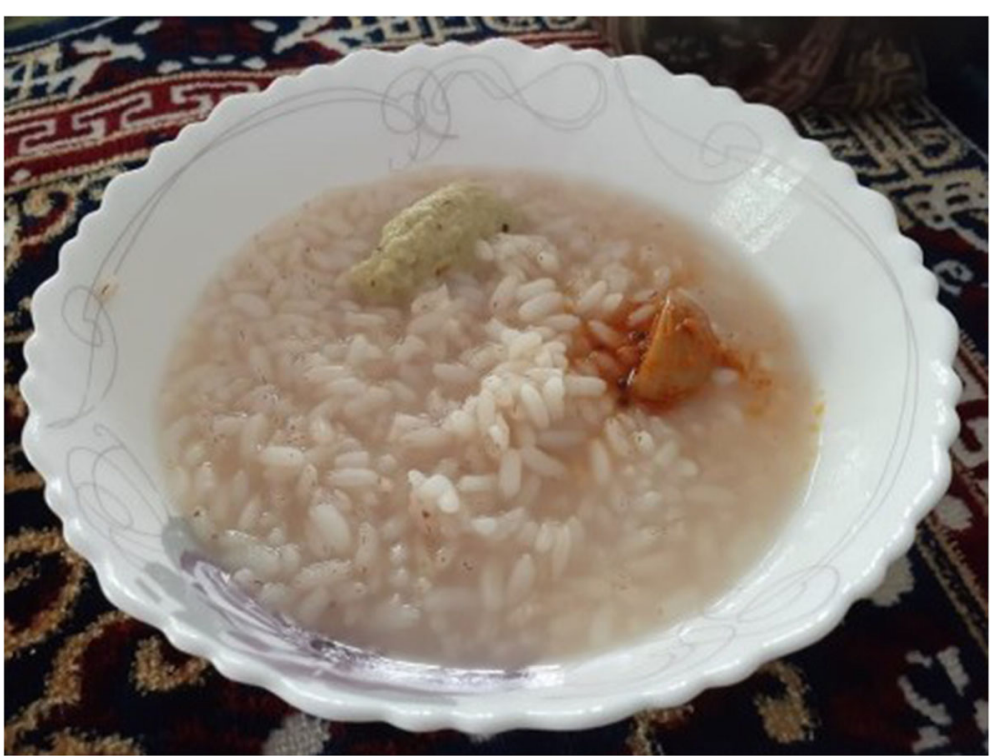

Fig. 2 Yavagu

food after sunset. This is important for asthma, diabetes and vata diseased patients.

\subsection{Food for mind}

In Ayurveda, foods are used to support and bring out the three qualities of mind. Foods which support sattwa are called sattvic foods. Foods which draw out raja are called rajasic foods, and the foods which increase tamas are called tamasic foods.

\subsubsection{Sattvic diet}

Sattvic means pure essence. This is the purest diet for a consciously spiritual and healthy life. It nourishes the body and maintains it in a peaceful state. According to Ayurveda, this is the best diet for physical strength, a

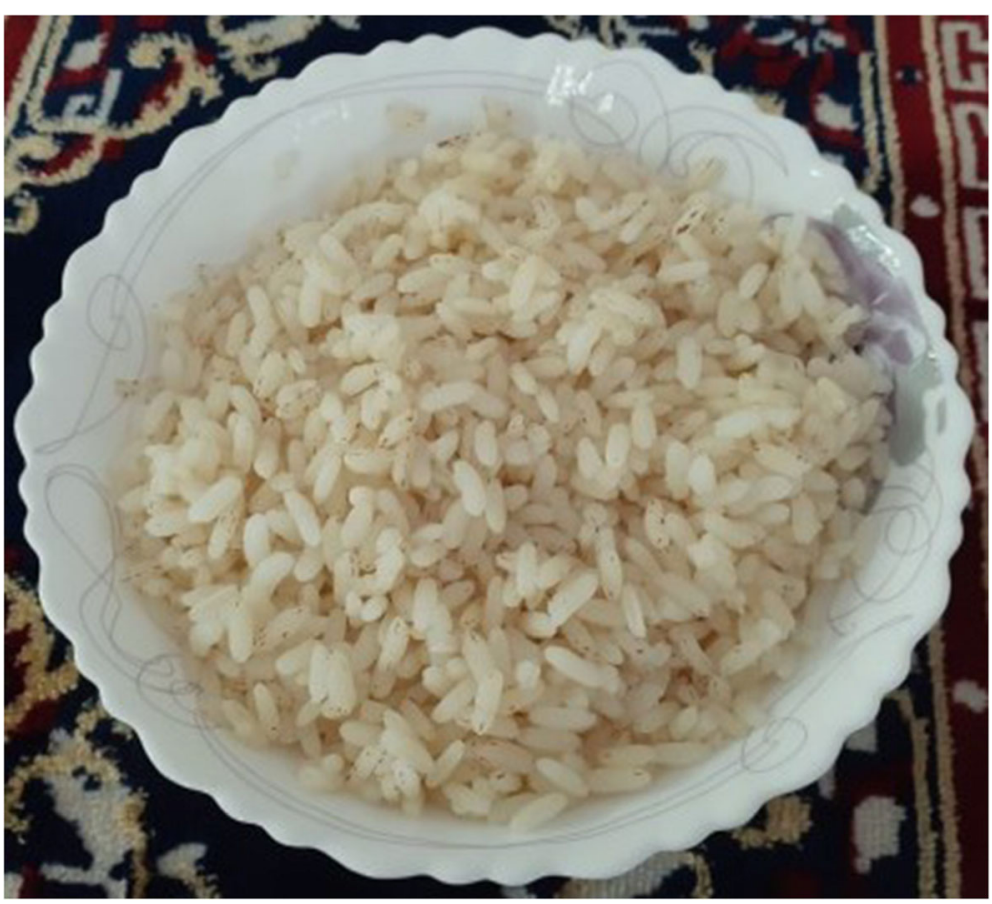

Fig. 3 Rice preparations 


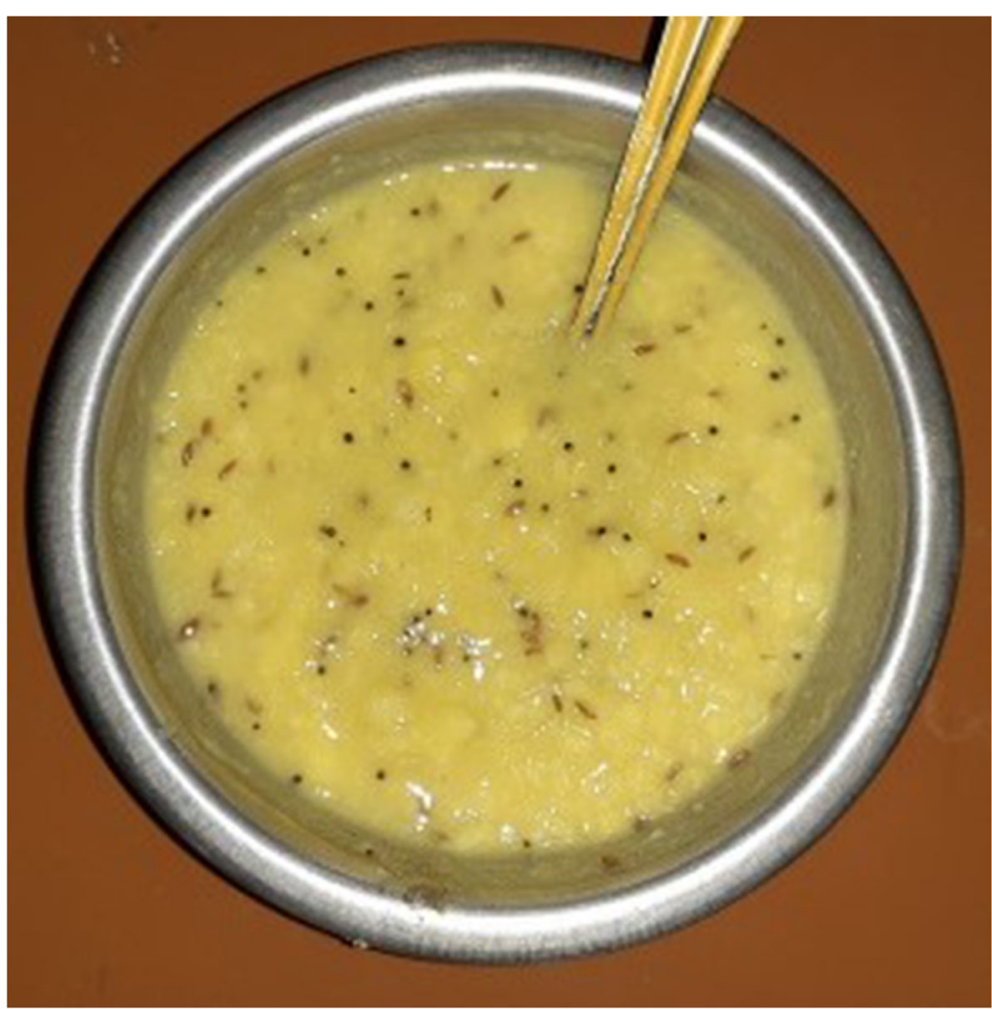

Fig. 4 Khichadi

good mind, good health, and longevity. And it calms and purifies the mind, enabling it to function at its maximum potential. A sattvic diet thus leads to true health: a peaceful mind in control of a fit body, with a balanced flow of energy between them. A sattvic diet is excellent for those individuals who desire to live a quiet, peaceful and meditative life. Sattvic foods include sprouted whole grains, fresh fruit, land and sea vegetables, pure fruit juices, nut and seed milk and cheese, legumes, nuts, seeds, sprouted seeds, honey and herbal teas. Sattvic foods are those foods which do not agitate your stomach at all (Fig. 1).

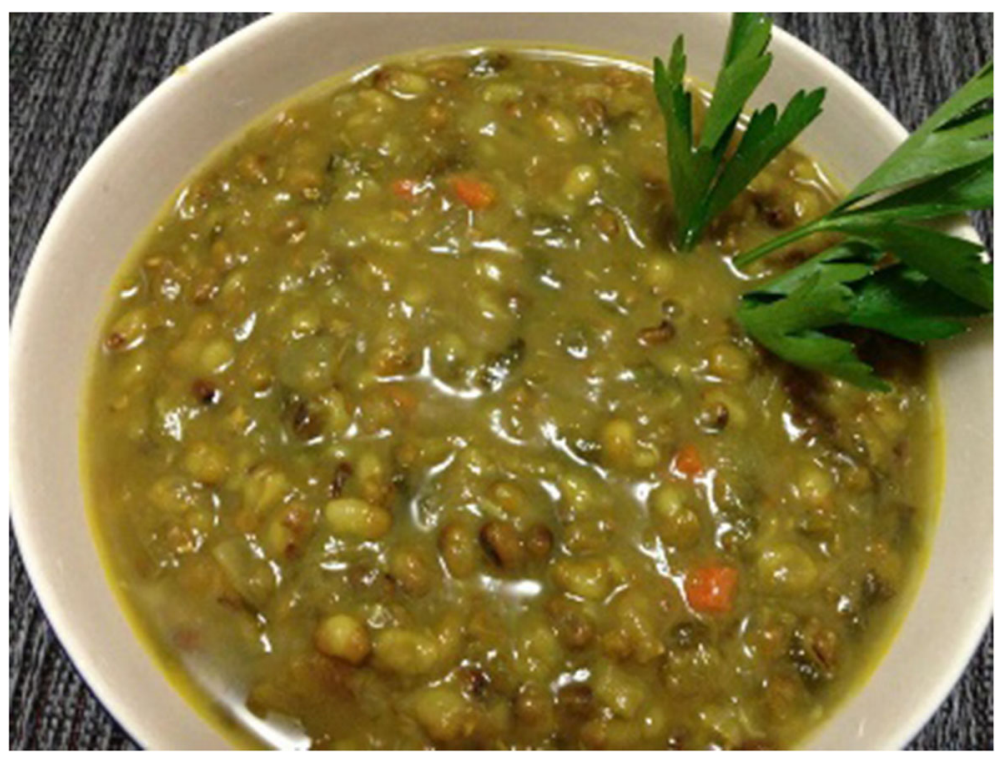

Fig. 5 Yusha 


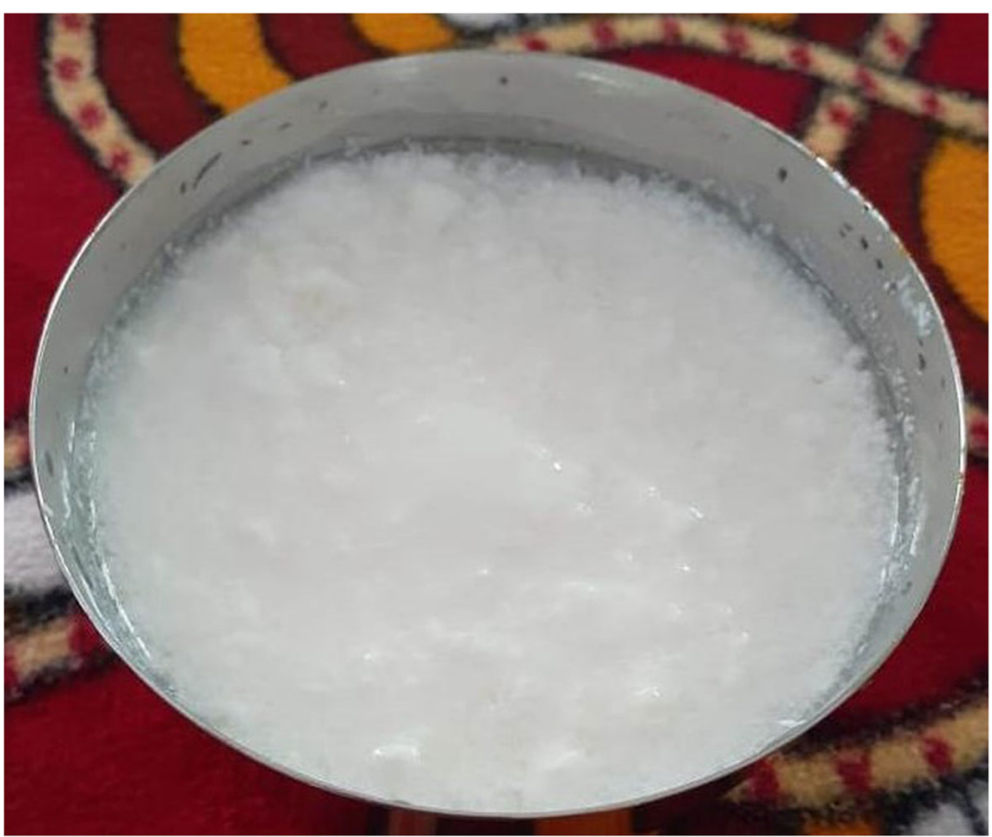

Fig. 6 Takra

\subsubsection{Rajasic diet}

According to Ayurveda, the foods which aggravate pitta and vata doshas and that which increase anger and restlessness are called rajasic foods. They stimulate more fire, outward motion, creativity, aggression and passion. It includes too much spicy, salty and sour foods. Sour and spicy preparations, pickles, tea, coffee, alcohol and vegetables like onion, garlic, etc. are said to be rajasic in nature. The mind-body equilibrium will be destroyed by rajasic foods and they make the mind restless and uncontrollable.

\subsubsection{Tamasic diet}

Foods that increase the inner darkness and confusion are called tamasic foods. Tamasic foods include fried and frozen foods, fast foods, microwaved foods, processed foods, left overnight foods, meat, fish, eggs, onion, alcohol, etc. They are good for slowing us down, numbing us, depressing us and enhancing inertia. Tamasic food is the unhealthiest food of all.

\subsection{Diet for doshic constitutions}

Tolerance of food, drinks, environment depends on the type of doshic constitution. By understanding the doshic

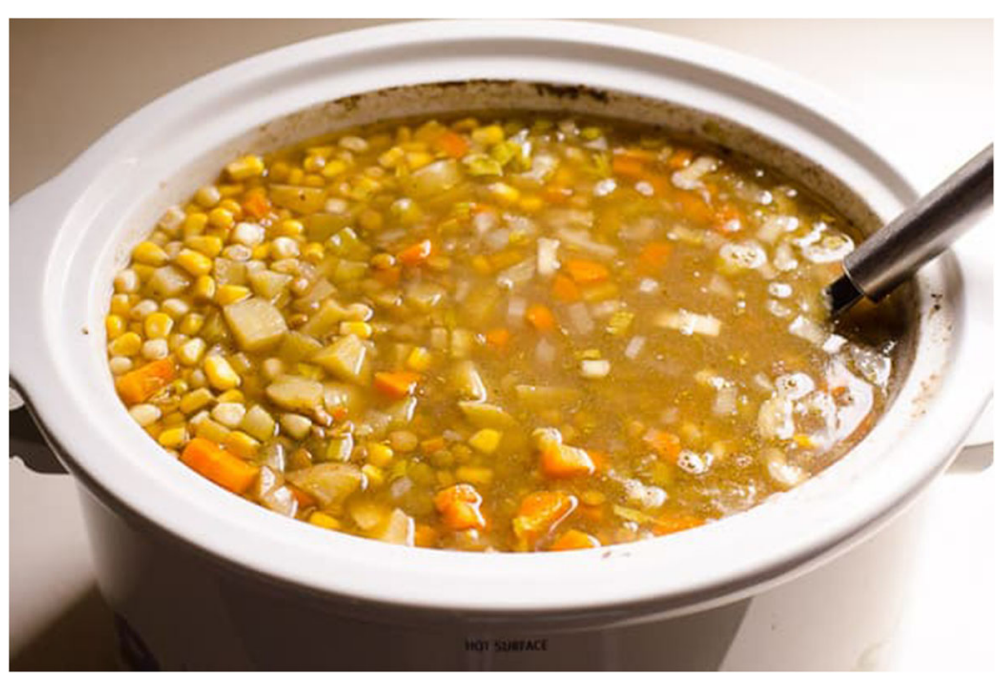

Fig. 7 Supa 
constitution of the individual, one can choose appropriate food, drinks and environment.

\subsubsection{Diet for vata constitution}

The functions of vata dosha in the body include movements in the body, process of elimination, controlling the nervous system, etc. The individuals with vata constitution possess dry, light, cold, quick, irregular and rough qualities. So they need smooth, heavy, warm qualities which are opposite to their own qualities. Vata people should take fresh, warm food with sweet, sour and salty tastes. They should avoid too much fasting and also the use of spicy food to regulate their digestion. Diet for vata constitution includes warm drinks, sweet fruits, raw nuts, milk, butter, cream, hot cereals, etc.

\subsubsection{Diet for pitta constitution}

Pitta persons have hot, penetrating or sharp, flowing liquid, slightly oily and light qualities in them. These persons should take food and drinks opposite to these qualities-cool, mild, maintaining dry and heavy qualities. Pitta accumulates in the rainy season and gets aggravated in October. Balancing and strengthening diet with mainly sweet, bitter and astringent will be perfect for this constitution. Cool foods and drinks, especially in hot weather and also eat a mostly vegetarian diet which suits the constitution, are preferred.
Adequate intake of raw food and juices are indicated. Cool water should be taken and coffee, alcohol, black teas, pickles, vinegar, chillies, vegetable oils, bakery products, canned foods, instant foods, hybrid grains, etc. should be avoided.

\subsubsection{Diet for kapha constitution}

The functions of kapha dosha in the body include protection, governs the structure of the body, provides immunity, holds the cells together, forms the muscle and bone, etc. The individuals with kapha have slimy, cold, heavy and soft qualities. They need foods and drinks which are opposite to their own qualities. So they need hard, warm, light foods with astringent, pungent and bitter tastes. They should prefer low carbohydrate, low-fat diets without sugars. The people with kapha constitution should avoid frequent eating, frozen edibles and cold water.

\subsection{Some traditional dietary preparations in Ayurveda} Ayurveda advocates more on the prevention rather than cure of diseases and obviously emphasizes on the ideal food to be consumed to attain and sustain good health. The below mentioned are some traditional dietary

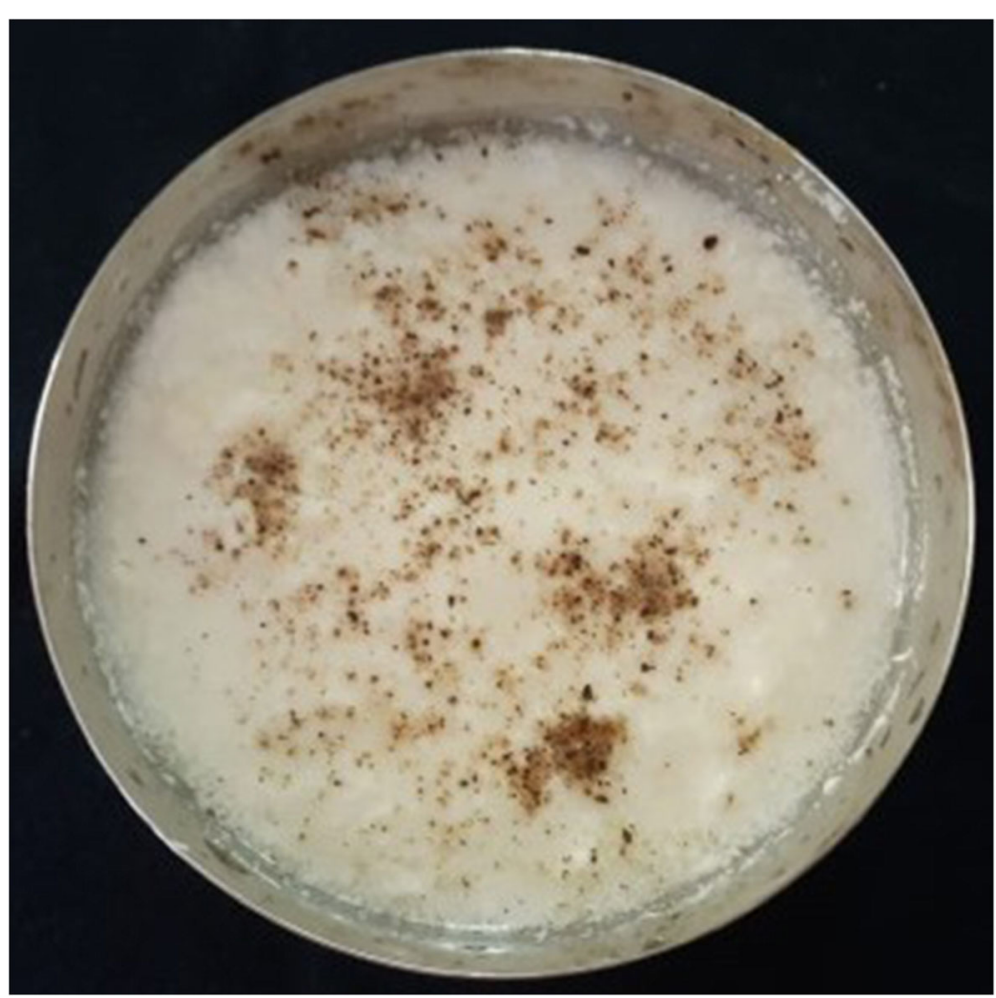

Fig. 8 Rasala 
Table 1 Showing general ratios of water to be added

\begin{tabular}{ll}
\hline Preparation & Ratio of water \\
\hline Manda & 14 times of water \\
Peya & Four times of water \\
Vilepi & Four times of water \\
Yavagu & Six times of water \\
Anna & Four times of water \\
\hline
\end{tabular}

preparations of Ayurveda which is called as pathya which means that which is wholesome and soothing to our body.

\subsubsection{Manda, Peya, Yavagu and Vilepi}

Rice has to be boiled over moderate fire until it gets properly cooked with water. Depending on the quantity of liquid and solid part taken from the cooked rice, it is categorized as shown in Table 1.

Manda: Only the supernatant liquid part is taken leaving the boiled rice

Peya: Equal solid rice and liquid portion are taken

Yavagu: More solid rice portion and less liquid part are taken together (Fig. 2)

Vilepi: Only solid rice part is obtained

\subsubsection{Anna kalpana (rice preparations)}

Properly washed rice is soaked in water until the rice particles swell a little and later boiled with water, filtered and the solid portion used (Fig. 3).

\subsubsection{Some other preparations}

Khichadi To prepare khichadi, tandula and simbi dhanya are taken in either in equal quantity, 1:1/2 ratio or $1: 1 / 4$ ratio as per the need. A little amount of sneha (oils), saindhava lavana (rock salt), ardraka (Zingiber officinale), hingu (asafoetida) and haridra (curcumin) are added to the preparation. The mixture is cooked in a vessel with six parts of water to attain a solid consistency. It alleviates kapha and pitta dosha, provides energy and subsides vata dosha (vata, pitta and kapha doshas are basic constituents of the body) (Fig. 4).

Yusha It is a semisolid preparation obtained by boiling one part of different types of dhanya visesha (kulattha, yava, mudga) along with one-eight quantity of sunthi (dried ginger), pippali and 16 parts of water (Fig. 5).

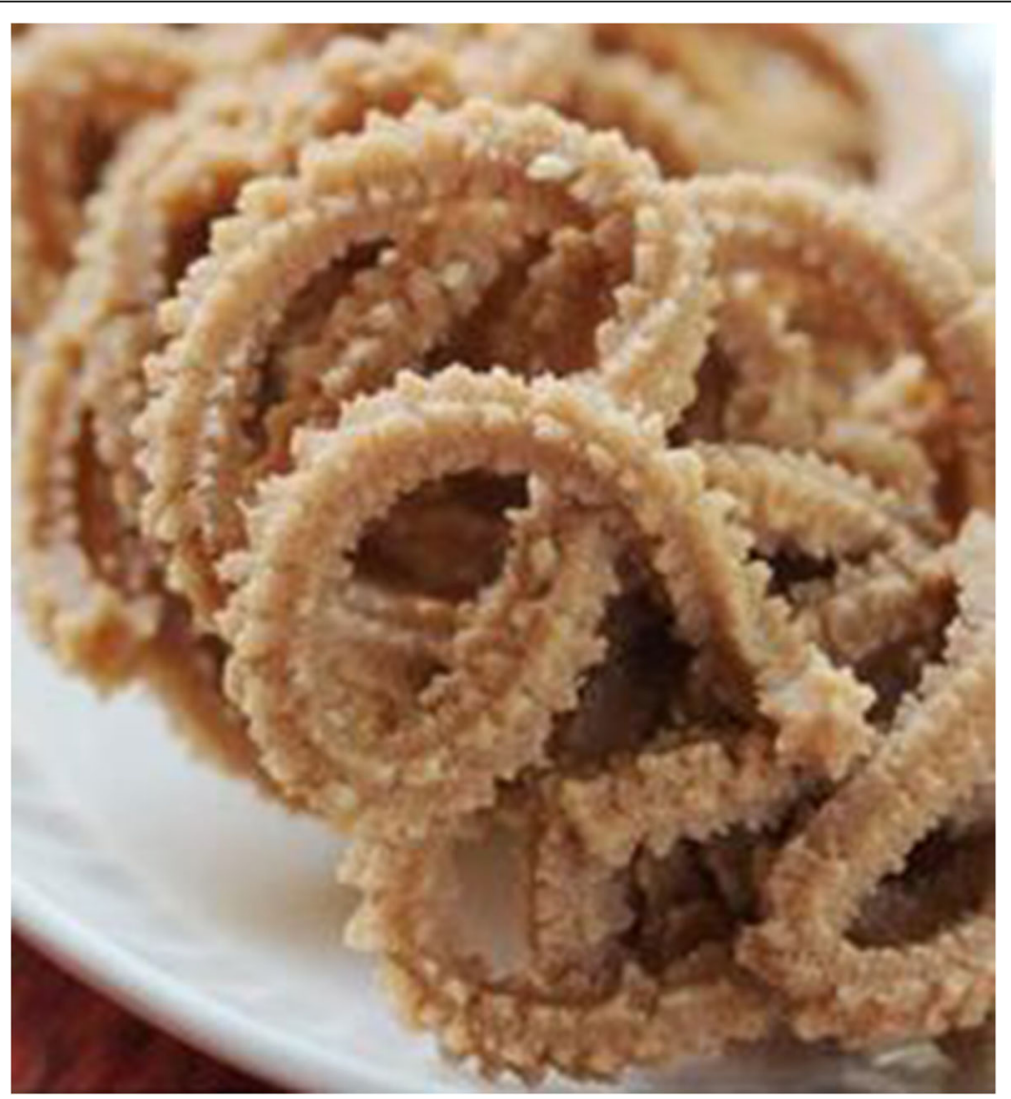

Fig. 9 Saskuli 
Takra It is a liquid preparation prepared by continuously churning the curd for one prahara $(3 \mathrm{~h})$ with different ratios of water added (Fig. 6).

Indications of takra

It is indicated in indigestion, piles, fever, diarrhoea, anaemia, dysentry, etc.

Kurchika The kurchika preparations are the inspissated milk or its products. Wherein the products are boiled to a diminished fluidity state.

Khada and Kambalika These two are the special preparations of yusha prepared by takra and any dhanya visesha.

Raga and Sadava These are prepared using juices of jambu, vrikshamla and parushaka with required quantity of mustard, sugar and salt added to it.

Saktu The churna of the roasted dhanya visesha is called as saktu. Wheat, barley, rice, ragi, maize, etc. are roasted properly and later brought into fine powder.

Supa It is the preparation where any of the simbi dhanya (red gram, green gram, etc.) are soaked, dehusked and boiled with enough quantity of water along with the required quantity of salt, oil/ghee and other spicy ingredients (Fig. 7).

Rasala To prepare this, the curd is added with the required quantity of sugar, chilly, ghee and honey. This is churned properly and added with little quantity of karpura for good odour (Fig. 8).
Visyandana Raw wheat flour is boiled with an equal quantity of ghee and milk to a state where it is neither solid nor too liquid.

Saskuli These may be prepared with rice, wheat, ragi, flour, etc. The flour is mixed with required quantity of tila, kamala kanda and water to bring it in paste form. A part of this paste is placed in a special instrument and pressed. The drug comes out in a thick thread form of special designs. This is put into edible oil placed over fire. After proper frying, it is taken out, allowed to cool down and used (Fig. 9).

Prithuka Any of the dhanya visesha is soaked in water, later roasted and pounded to separate the husk part and the preparation will be called as prthuka.

Mamsa rasa A soup prepared by boiling chopped meat with required quantity of water. Two, four, six or eight times of water are added considering the nature of meat with the chopped mamsa and boiled over moderate fire to get it in desired consistency (Fig. 10).

Vesavara Boneless meat is steamed and smashed. It is boiled with the required quantity of guda, ghrita, pippali churna, marica churna, sunthi, lavana, etc. along with enough quantity of water.

\section{Discussion}

Through centuries, food has played a vital role for human beings in health and disease. The history of man to a great extent has been a struggle to obtain food.

Fig. 10 Mamsa rasa

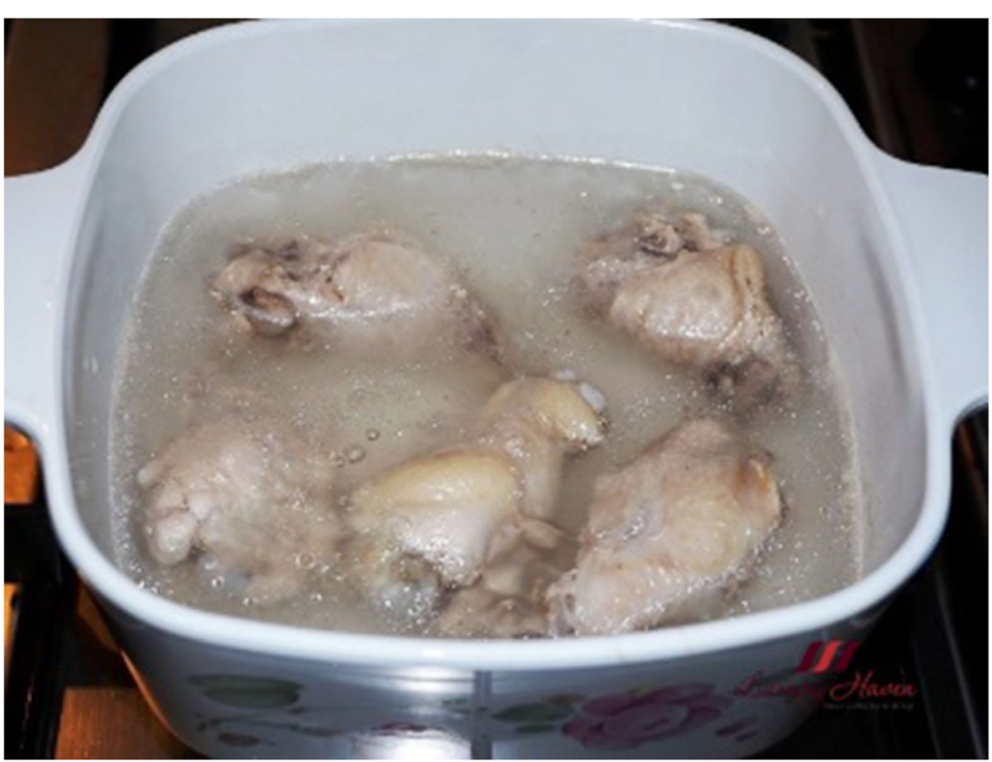


Ayurveda is a healing science which considers food as a major therapeutic tool. Ayurveda recommends us to eat sattvic (pure and fresh) foods avoiding rajasic (fiery) and tamasic (spoiled) foods. Sattvic foods are fresh and light and help to clear the mind. Ayurvedic food habits help us to regularize absorption, assimilation and elimination. The role of food on the behaviour and character of a person is not negligible. As our food will be pure and natural, our brain will also be healthy and active. Ayurvedic food habits help in strengthening immune systems and assisting the gut in functioning more effectively. With a clear mind and a healthy body, one can more easily fulfil one's soul purposes.

\section{Conclusion}

Ayurveda, a traditional system of medicine that originated over three millennia ago in the South Asian region, offers extensive insights about food and health based on certain unique conceptual as well as theoretical positions [4]. There has been an increased global interest in traditional medicine. Efforts to monitor and regulate traditional herbal medicine are underway [5]. Food is an essential requirement in life and one can attain good health by following a proper, natural diet. Most health problems develop due to the wrong eating habits and cooking methods. Out of the three upasthambhas (supports of life), i.e. ahara (diet), nidra (sleep) and brahmacharya (observance of celibacy); the first one has been given more importance and considered to be the best in Ayurveda. A proper, optimum and skillful use of these triads, human body to maintain its integrity, being enriched with bala (physical and immunological strength), varna (complexion) and upachaya (growth of nourishment), till full length of life, provided the person concerned does not get involved in the regimen detrimental to health.

\section{Acknowledgements}

The authors thank Mr Ranjit, Amarnath and Prof S. Radhamaniamma for their moral support, financial support and inspiration for the completion of my work.

\section{Authors' contributions}

DS is the main author. RNV and AM guided and gave valuable suggestions and inspired for the completion of this work. All authors read and approved the final manuscript.

\section{Funding}

Nil.

\section{Availability of data and materials}

The data supporting the findings are obtained from the classical textbooks of Ayurveda like (1) Charaka Samhita, (2) Susruta Samhita, (3) Ashtanga Hridaya, (4) Sarngadhara Samhita, (5) Kaiyyadeva Nighantu.

\section{Competing interests}

The authors declare that they have no competing interests.
Received: 2 May 2019 Accepted: 12 September 2019

Published online: 07 November 2019

\section{References}

1. Sarkar P, kumar L, dhumal C, Panigrahi SS, Choudhary R. Traditional and ayurvedic foods of Indian origin. J Ethnic Foods. 2015;2:97-109.

2. Payyappallimana U, Venkatasubramanian P. Exploring Ayurvedic knowledge on food and health for providing innovative solutions to contemporary healthcare. Front Public Health. 2016:4:1.

3. Sharma P. Charaka Samhita of Agnivesa, English translation. 1; 2010. p. 193.

4. Payyappallimana U, Venkatasubramanian P. Exploring Ayurvedic knowledge on food and health for providing innovative solutions to contemporary healthcare. Front Public Health. 2016:4:1.

5. Pandey MM, Rastogi S, Rawat AKS. Indian traditional Ayurvedic system of medicine and nutritional supplementation. Evid Based Complement Alternat Med. 2013;2013:1.

\section{Publisher's Note}

Springer Nature remains neutral with regard to jurisdictional claims in published maps and institutional affiliations. 